\title{
Claude Lévi-strauss: En el centenario de su nacimiento
}

\author{
Hernán Amat Olazábal \\ maheramo@yahoo.com \\ Departamento de Arqueología. UNMSM
}

Claude Lévi-Strauss, uno de los más brillantes pensadores franceses del siglo XX, cumplirá en noviembre próximo 100 años de existencia, asombrosamente fructífera y admirablemente lúcida. Como sucede con otros pensadores de la talla de Einstein, Darwin, Marx, Freud, Chomsky, y muchos otros autores célebres, habría que juzgar a Lévi-Strauss, en dos planos distintos: como el pensador original de primera magnitud, y como el filósofo y antropólogo fundador del estructuralismo, de la misma forma que Jean Paul Sartre fue el creador del existencialismo.

Lévi Strauss nació en Bruselas, el 28 de noviembre de 1908. Su padre, de origen francés, era un artista judío-agnóstico que crió a su hijo en un ambiente que combinaba la cultura artística y el escepticismo. Lévi-Strauss es, sin duda, una de las figuras descollantes de la antropología y el introductor a las ciencias sociales del enfoque estructuralista. $\mathrm{Su}$ carrera académica estuvo asociada con Marcel Mauss, el principal discípulo y colaborador de Durkhiem, y en la obra de Ferdinand Saussure. La preocupación básica de Lévi-Strauss es nada menos que la estructura del espíritu humano, entendiendo por estructura, no una articulación que pueda observarse directamente, sino, más bien, una ordenación lógica, un conjunto de ecuaciones matemáticas de las que se puede demostrar que son funcionalmente equivalentes, como es un modelo, al fenómeno en discusión. El estructuralismo como entendimiento de la totalidad para comprender cada uno de los elementos constitutivos.

Se dijo alguna vez que Lévi-Strauss "era el hijo de la hermana de Marcel Mauss, y el heredero directo de Emile Durkhiem por herencia materna”. Estudió Derecho y Filosofía en la Sorbona, concluyó sus estudios de filosofía en 1931. Después de unos pocos años de enseñanza secundaria, fue invitado para formar parte de la misión cultural francesa en Brasil, país donde vivió de 1935 a 1939, y se desempeñó como profesor visitante de sociología en la Universidad de Sao Paulo, centro académico fundado por los franceses. Al empezar la Segunda Guerra Mundial, volvió a Francia y pasó un año en el servicio militar. En 1940, fue designado subdirector del Musée de l'Homme.

Después de la ocupación alemana, viajó hacia las islas de Martinica y Puerto Rico y, finalmente, Nueva York, donde Robert Lowie y Alfred Metraux le facilitaron un trabajo en la New School. En Nueva York, conoció a Jean Paul Sartre, con quien discutiría distintos temas por espacio de varios lustros. Durante su permanencia en Brasil, realizó su primer trabajo etnográfico de campo en el Mato Grosso y en la floresta tropical del Amazonas. 
Aquella extraordinaria experiencia sentó las bases de su identidad como antropólogo. En 1945, visitó nuevamente los principales círculos académicos de Nueva York; desempeñó brevemente el cargo de adjunto cultural de la Embajada Francesa en Washington (19461947). Los años de permanencia en los Estados Unidos le sirvieron en muchos aspectos: tratar con eminentes antropólogos como Franz Boas, y relacionarse con Roman Jakobson (figura destacada del estructuralismo), quien contribuyó a configurar su perspectiva teórica. A su retorno a París, presentó su tesina y tesis (1948). Recibió su doctorado en la Sorbona, por su tesis "mayor" y "menor": Las estructuras elementales del parentesco y La vida familiar y social de los indios Nambikwara, respectivamente. En 1953, se le nombró Secretario General del Consejo Internacional de las Ciencias Sociales. Se desempeñó como profesor del Collège de France de antropología social desde 1959 hasta su jubilación, en 1982.

El estudio del estructuralismo es una de las contribuciones teóricas de la moderna antropología, que ha influido en otras ciencias naturales y humanas. Leímos con pasión Tristes trópicos y enseguida revisamos con entusiasmo creciente Antropología estructural, El totemismo en la actualidad, El pensamiento salvaje y Lo crudo y lo cocido. "Nadie es el mismo tras la lectura de las obras de Lévi-Strauss" ha dicho con justa razón Yvan Simonis, uno de sus connotados exegetas.

$\mathrm{Su}$ tesis "mayor", Las estructuras elementales del parentesco, publicada en 1949, y dedicada a la memoria de Lewis H. Morgan, constituye un estudio técnico, de lectura difícil, dedicada esencialmente a un amplio análisis comparativo de las reglas formales de matrimonio entre los aborígenes australianos y otras poblaciones tribales del sudeste asiático. Mientras que antropólogos como Radcliffe-Brown sostenían que los parentescos estaban basados en la descendencia de un ancestro común, Lévi-Strauss pensaba que estos parentescos tenían más que ver con la alianza entre dos familias, que resulta de un intercambio contractual, cuando la mujer de un grupo se casa con el hombre de otro grupo.

En el prefacio de la primera edición de Las estructuras elementales del parentesco, Lévi-Strauss escribe:

"Entendemos por estructuras elementales del parentesco los sistemas cuya nomenclatura permite determinar en forma inmediata el círculo de los parientes y el de los allegados; vale decir, los sistemas que prescriben el matrimonio con cierto tipo de parientes o, si se prefiere, aquellos sistemas que, al definir a todos los miembros del grupo como parientes, distinguen en ellos dos categorías: los cónyuges posibles y los cónyuges prohibidos". Y concluye enfatizando que "un triple fin nos hizo dedicar nuestro trabajo a la memoria de Lewis H. Morgan: rendir homenaje al gran iniciador de un orden de investigaciones que luego retomamos con modestia; reverenciar a través de él, a la escuela antropológica americana que fundó y que, durante cuatro años, nos asoció de manera fraternal con sus trabajos y sus discusiones".

Así pues, en lo que se conoce como "la teoría de la alianza", Lévi-Strauss recalca la importancia del matrimonio en la sociedad como algo opuesto a la importancia de la descendencia. El postulado básico radica en que el intercambio de las mujeres entre los grupos de hombres de una sociedad, tiene como resultado, una mayor solidaridad social y una mayor oportunidad de sobrevivir para todos miembros de una sociedad. En la tesis "menor", La vida familiar y social de los indios Nambikwara, analiza con profundidad, la posición de la mujer en las sociedades no occidentales, recibió una crítica elogiosa de Simone de Beauvoir y de numerosos antropólogos sociales.

En Elpensamiento salvaje, Lévi-Strauss tiende un arco que une dos elementos contrarios: la naturaleza y la cultura. En esta obra de corte filosófico describe el pensamiento de las sociedades primitivas y lo compara con el de las históricas. El adjetivo histórico no quiere decir que los primitivos carezcan de historia; del mismo modo que en nuestro mundo el 
pensamiento salvaje ocupa un lugar marginal y casi subterráneo, la noción de historia no tiene entre los primitivos la jerarquía suprema que nosotros le otorgamos. Una vez más, su lógica no es distinta a la nuestra por lo que toca a su forma de operación aunque sí lo sea por sus objetos y por los fines a que aplica su razonamiento. Por ejemplo, entre los primitivos, los sistemas de clasificación que comprende el rubro general de taxonomía no son menos exactos que los de nuestras ciencias naturales, y son más ricos.

Un rasgo característico de El pensamiento salvaje es que los individuos que se comunican se encuentran siempre en relación directa, de forma que discursos y acciones no son claramente diferenciales, como sucede, habitualmente, entre los pueblos que conocen la escritura. En estas civilizaciones las palabras no solo son medios para transmitir información, sino que son también un medio para acumularla. Recíprocamente, esto origina un problema que LéviStrauss ha abordado de una forma original y de inusitado interés. Todas las culturas, sean 'primitivas' o complejas, se enfrentan con el problema de la acumulación y recuperación de información. Nuestros contemporáneos 'primitivos' como los aborígenes australianos y los bosquimanos del Kalahari, están muy lejos de ser ignorantes o nómades locos. Por el contrario, poseen un profundo conocimiento de los recursos de su medio ambiente y son capaces de vivir dentro de un relativo 'confort' en lugares que los civilizados consideran inhabitables. ¿Cómo es ello posible? ¿Cómo se las ingenian, sin libros u otros medios para acumular información necesaria y transmitirla de generación en generación?

Lévi-Strauss ha respondido a esta problemática más o menos con el siguiente argumento: cuando nuestra civilización acumula información en libros, cintas magnetofónicas o discos lo hace mediante códigos estructurados. Determinados objetos del mundo exterior, especialmente destinados para este uso, son sometidos a un proceso de ordenación que sirve para acumular la información; otras personas que utilicen el mismo código pueden recuperar la información analizando las pautas impuestas a estos objetos materiales. En la sociedades ágrafas y en las civilizadas, todos los objetos del mundo exterior ordenados por su simple subordinación a las categorías verbales; la forma de clasificar las cosas del mundo exterior constituye por sí misma una manera de acumular información. Las palabras de una lengua vernácula -afirma Lévi-Strauss- no reflejan clases naturales, sino serie de cosas dotadas de valor para la persona que habla. La forma de asociar y ordenar estas palabras, una con respecto a otras, permite acumular información de la misma forma que sucede con la forma de disponer las letras en una página de un libro.

Tristes trópicos, es el título de una de las obras maestras de Lévi-Strauss, escrita entre el 12-X-1954 a 5-III-1955. Relata en una prosa diáfana y exquisita, acerca de sus viajes y estudios etnológicos a la selva amazónica de Brasil y al Asia. No solo se registra en aquella enjundiosa obra las ricas experiencias del autor en sociedades precapitalistas que estudió exhaustivamente, también se desprende de esta suerte de autobiografía espiritual una teoría del viaje, no concebido como un desplazamiento en el espacio, sino sincrónicamente inscrito en el tiempo, en el espacio y en la jerarquía social. Uno de los capítulos más interesantes de Tristes trópicos, es: "Una sociedad indígena y su estilo". Al lector interesado en captar el significado de las "variaciones sobre un tema" del pensamiento estructuralista, le recomendamos la lectura de este capítulo que empieza como así:

El conjunto de las costumbres de un pueblo tiene siempre un estilo peculiar; dichas costumbres forman sistemas. Estoy convencido de que estos sistemas no existen en número ilimitado, y que las sociedades humanas, como los individuos -en sus juegos, sus sueños o sus delirios- jamás crean de forma absoluta; todo lo que pueden hacer es limitarse a escoger ciertas combinaciones en un repertorio ideal que sería posible reconstruir. Haciendo el inventario de todas las costumbres observadas, 
de todas las imaginadas en los mitos, así como las evocadas en los juegos de los niños y de los adultos, los sueños de los individuos sanos y enfermos y las conductas psicopatológicas, llegaríamos a construir una especie de tabla periódica semejante a la de los elementos químicos (pág. 82).

En la última página (418) de Tristes trópicos, Lévi Strauss dice:

Si el individuo ya no está solo en el grupo y cada sociedad ya no está entre las otras, el hombre no está solo en el universo: cuando el arco iris de las culturas humanas termine de abismarse en el vacío perforado por nuestro furor, en tanto que estemos allí y que exista un mundo, ese arco tenue que nos une a lo inaccesible permanecerá, mostrando el camino inverso al de nuestra esclavitud.

En 1958 aparece su Antropología estructural, la cual causó diversos comentarios en Europa y Estados Unidos; ella trata de lo que él consideraba que eran los principios generales de la información del pensamiento válidos para todas las mentes humanas. En aquel momento, Lévi-Strauss era el teórico antropológico más influyente en Francia, secundado por muchos, el autor más leído en las esferas científicas y académicas y su nombre era conocido en todo el mundo.

¿Qué es estructura? Este término ha sido el motivo de una profunda preocupación a lo largo de toda la frondosa obra de Lévi-Strauss. Él mismo nos da una definición:

Primero, las estructuras no son manifestaciones concretas de la realidad; son modelos cognitivos de la realidad. Como tales, las estructuras se encontrarán como modelos mentales, tanto en el hombre primitivo como en el científico: los modelos científicos son útiles para entender su particular campo de estudio; las estructuras mentales del hombre primitivo (o moderno), que puede ser consciente o inconsciente, le ayuda llevar su vida diaria. El hombre comprende su universo y orienta su conducta sobre la base de estos procesos mentales.

Precisamente, uno los aportes fundamentales de Lévi-Strauss a las Ciencias Sociales, se relaciona con los procesos mentales humanos, que son los mismos en todas las sociedades y culturas, aunque las manifestaciones pueden ser distintas. Esta unidad de los procesos mentales proviene del cerebro humano y de la manera en que funciona. Esta unidad tiene como resultado la clasificación del universo por el hombre moderno, se basa en las mismas premisas que cuando lo hace cualquier hombre 'primitivo', interpretando las realidades eternas a través de modelos.

De otro lado, los estudios de Lévi-Strauss sobre la "ciencia de los mitos" son tan relevantes como su preocupación por los procesos mentales. En 1962 aparecieron sus obras sobre El totemismo en la actualidad y El pensamiento salvaje (según sus palabras, aquel libro es una suerte de prefacio de éste y a su vez será prefacio de otro libro). En la década de los setenta, inició un trabajo muy extenso, monumental, en cuatro volúmenes, llamado Mitológicas: I. Lo crudo y lo cocido, II. De la miel a las cenizas, III. El origen de las maneras de mesa, y IV. El hombre desnudo.

En estas obras se analizan ciertas características estructurales que hacen posible el estudio comparativo del mito. Lo crudo y lo cocido es una obra particularmente difícil, pero recorrer la sinuosa peregrinación del autor a través de la maraña de los mitos de los indígenas bororo y ge de la Amazonía, es realmente fascinante, muchos pasajes de esa 'sinfonía' del entendimiento nos exaltaron, otros nos iluminaron y otros más nos intrigaron. En la obertura de este primer volumen de Mitológicas: Lo crudo y lo cocido, Lévi-Strauss inicia su estudio, con las palabras siguientes:

El objeto de este libro es mostrar de qué modo categorías empíricas, tales como lo crudo y lo cocido, fresco y podrido, mojado y quemado, etc., definibles con precisión por la pura observación etnográfica y adoptando en cada ocasión el punto de vista de 
una cultura particular, pueden sin embargo servir de herramientas conceptuales para desprender nociones abstractas y encadenarlas en proposiciones.

Ello indica que la utilización de los análisis estructuralistas del mito permite la reducción del material a proporciones manejables, como resultado de la idea conseguida por esta utilización de los hechos que se están estudiando. Sin esta reducción del volumen del material sobre el mito no sería posible el estudio de varias culturas sobre el mito.

En Mitológicas II: De la miel a las cenizas, las creaciones de los aborígenes de Sudamérica son exhaustivamente analizadas por el autor, es decir, ahondando el desarrollo del análisis estructural del pensamiento mítico; y comprende que para su logro debe recurrirse a varios tipos de modelos. Y, hace hincapié que las metáforas inspiradas por la miel se encuentran entre las más antiguas y más difundidas. "Más dulces que la miel", la miel como ofrenda a los dioses entre los babilonios, o la miel como ofrenda a los muertos se registra en la Ilíada, etc. Hoy, es frecuente emplear las locuciones "dulce como la miel", "todo miel", "la miel de tus labios". Así, la trama de los mitos se desenvuelven entre "la miel" y su opuesto "la ceniza".

En Mitológicas III: El origen de las maneras de mesa, Lévi- Strauss dice que este libro forma un todo, como los dos que le preceden. El argumento central de esta obra es el mito de los indios Tukuna de Norte América. Señala el autor que "ningún otro mito ha sido objeto por nuestra parte de un análisis tan hondo, desde varios puntos de vista, sucesivos o simultáneos: textual, formal, etnográfico, semántico...”; y añade que la primera parte del libro sirve para iniciarse en el método estructural, familiarizarse progresivamente con sus procedimientos y sus vías, y, luego, "juzgar sus méritos por los resultados".

Mitológicas IV: El hombre desnudo (dedicado a su madre, "en el año de sus ochenta y cinco, y en memoria de mi padre") es el final de esta impresionante serie. En ese voluminoso estudio, Lévi-Strauss concluye la demostración que, según sus críticos, tardará en ser repetida a semejante escala, acerca de lo fecundo y útil del análisis estructural aplicado a los mitos, acaso sea lo más valioso el balance final, rico también en conclusiones.

Los mitos -dice el autor- nos enseñan mucho sobre las sociedades de las que proceden, ayudan a exponer los resortes intimos de su funcionamiento, esclarecen la razón de ser de creencias, de costumbres y de instituciones cuyo plan parecía incomprensible. En fin, y sobre todo, permiten deslindar ciertos modos de operación del espiritu humano, tan constantes en el correr de los siglos y tan generalmente difundidos sobre inmensos espacios.

En otro de sus libros titulado Mito y significado, aclara que no es posible el dominio de la naturaleza por el mito y dilucida cuestiones tan complejas como la relación entre mito e historia, la parte que ocupa las narraciones mitológicas en la cultura, sus conexiones con la ciencia y la música, etc.

Mirando a los lejos, es una de sus últimas obras que, según el autor, es la virtual continuación de Antropología estructural. Reflexiona sobre un problema importante de la condición humana, las relaciones entre la coacción y la libertad. Allanando el camino entre las instituciones, los hábitos, los mitos, los ritos y las creencias de las asociaciones más diversas, se aproxima progresivamente a la nuestra. A diferencia de otros opuestos, la coacción, lejos de oponerse se complementa con la libertad. En otro pasaje, aborda el carácter relativo de la idea de libertad: las libertades privilegiadas de la nobleza, inmunidades del clero y corporaciones burguesas en Francia antes de 1789, obstaculizaba otras libertades, concretas e históricas., más aún, en los países que hoy llaman subdesarrollados, en los cuales, “...con la Declaración Internacional de los Derechos de 1948 -dice Lévi-Strauss- 
hemos llevado, si no aun impuesto fórmulas que, en el estado donde se encontraban o donde muchos se encuentran aún, perdieron totalmente su significado. A las víctimas del hambre y de otras miserias fisiológicas o morales les importaría sin duda poco, si su condición debiera cambiar, que lo fuera a ambientes que nosotros mismos juzgaríamos insoportables" (Mirando a lo lejos. 1986: 340).

Un aspecto muy discutido por sus seguidores es aquél en el que el propio Lévi-Strauss afirma insistentemente que es marxista, y en muchos pasajes de su obra utiliza términos específicamente marxistas como el de praxis. Se refiere igualmente a la "innegable primacía de las infraestructuras", tal como leemos en su Pensamiento salvaje (cuya primera edición francesa apareció en 1962). Ello significa que el estilo de una cultura está limitado por el estado de su tecnología, que a su vez depende del entorno, y por el grado de transformación que haya sufrido aquel entorno a consecuencia de la acción humana. Pero, en ocasiones, la posición de Lévi-Strauss acerca del determinismo histórico no es muy firme, pues subraya constantemente la enorme variabilidad de la cultura e insiste más en la interdependencia recíproca de las variaciones que en su desarrollo cronológico o en la superioridad de un sistema sobre otro. En varios de sus escritos, Lévi-Strauss invita a relacionar su evolución intelectual en la lectura de Freud, con su pasión por la geología y sus descubrimientos de Marx -"mis tres amantes"-, como él los llama. Citemos lo que escribió sobre Marx:

La lectura de Marx me había impresionado en la medida en que era la primera vez que tomaba contacto, a través de ese gran pensamiento, con la corriente filosófica que va de Kant a Hegel: todo un mundo se me reveló. Desde entonces, ese fervor nunca será desmentido. Después de Rousseau, y en forma que me parece decisiva, Marx nos ha enseñado que la ciencia social se elabora a nivel de los acontecimientos, ni más ni menos que la física a partir de los datos de la sensibilidad. (Tristes trópicos: 44).

La Geología, Freud y Marx despertaron en Lévi-Strauss la intuición a la que se atiene, fuente permanente de su interés por lo racional del "significante", preocupación auténtica por la interferencia del inconsciente en la razón consciente. En la vasta obra de LéviStrauss se advierte un marcado énfasis en la dialéctica. Cada tesis engendra su antítesis, y la oposición entre la tesis y la antítesis se resuelve en una síntesis mediadora, que a su vez genera una nueva antítesis. Como se sabe para Hegel este era el proceso del desarrollo de las ideas, en cambio, para Marx el proceso del desarrollo es determinado por los sistemas político-económicos; para Lévi-Strauss es la dialéctica, como una característica básica del espíritu humano que se expresa en las clasificaciones verbales, en los mitos o en la diferentes formas de regular el matrimonio y las relaciones de parentesco.

Ampliaremos estos conceptos. Si el marxismo es una concepción histórica de la naturaleza, también es una concepción materialista de la historia: la praxis, "el proceso vital real", es el ser del hombre y su conciencia no es sino el reflejo de la materia que la praxis ha vuelto histórica. La conciencia y el pensamiento humano son productos no de la naturaleza, sino de la naturaleza histórica, es decir, de la sociedad y su modo de producción. Ni la naturaleza ni el pensamiento aislado definen al hombre sino la actividad práctica, el trabajo: la historia. Lévi-Strauss dice, al final de El pensamiento salvaje, que la praxis solo puede concebirse a condición de que exista antes el pensamiento, bajo la "forma de una estructura objetiva del psiquismo y del cerebro". El espíritu es algo dado y constituido desde el principio. Es una realidad insensible a la acción de la historia y a los modos de producción porque es un objeto físico-químico, un aparato que combina las llamadas y las respuestas de las células cerebrales ante los estímulos exteriores. En la praxis, el espíritu repite la misma operación que en el momento de elaborar las prácticas: 
separa, combina y emite. El espíritu transforma lo sensible en signos. En la concepción de Marx, es la primacía de lo histórico: el modo de producción social; en Lévi-Strauss, la de lo químico-biológico: modo de operación natural. Para Marx, la conciencia cambia con la historia; para Lévi-Strauss, el espíritu humano no cambia: su reino no es el de la historia, sino el de la naturaleza.

Nos remitiremos nuevamente a Tristes trópicos: en uno de los últimos pasajes dice que la civilización es un "mecanismo prodigiosamente complejo" cuya "verdadera función es simplemente incrementar la entropía del universo". Y la siguiente posición implica una especie de determinismo histórico: "Al desplazarse en su medio, el hombre transporta consigo todas las posiciones que ha ocupado en el pasado y todas las que ocupará en el futuro".

Philippe Simmonot entrevistó a Lévi Strauus, en noviembre de 1986, al cumplir 77 años de edad, después de la desaparición de Sartre y Raymond Aron. La extensa entrevista exaltaba a Lévi-Strauss como el fundador del estructuralismo, uno de los más poderosos cerebros de nuestro tiempo, el último gigante $\mathrm{y}$, añade que su obra ejerce una influencia decisiva en las Ciencias Sociales, rebasando ampliamente su disciplina original, la Etnografía.

En aquella entrevista, Simmonot preguntó a Lévi-Strauss, entre otros temas: ¿Por qué Sartre estuvo en desacuerdo con Ud.? La respuesta noble y luminosa es como sigue:

"Es algo más complejo. Primero, no hay ninguna duda de que Sartre era un gigante del pensamiento y que nos aplastaba con su prodigiosa capacidad para expresarse en los géneros más diversos: teatro, periodismo, filosofía, novela, digamos que Sartre se encontraba en un cielo más alto que el de sus contemporáneos. Dicho esto, creo que Sartre desarrolló, esencialmente una filosofía del sujeto. De hecho, desde Descartes, la filosofía francesa está dominada por la noción de sujeto. Si se quiere llegar a otras verdades, es necesario escoger un punto de vista diferente".

Otra pregunta interesante formulada por Simmonot fue: ¿Qué diferencia hay entre el pensamiento mitológico y el pensamiento religioso?

"La diferencia es fundamental -responde Lévi Strauss-. El pensamiento mitológico desborda todas las categorías; se esfuerza por responder a todos los problemas que el hombre puede plantearse; religiosos, metafísicos, también físicos, sociológicos, jurídicos, sicológicos, estéticos y pretende hacer a la vez lo que hace la religión y lo que más tarde hará la ciencia. En cuanto a nuestras religiones, éstas sólo buscan responder a ciertos problemas y lo hacen basándose en la idea (que siempre me ha sido extraña) de la posibilidad de una conversación personal entre Pedro, Pablo o Juan y una entidad sobrenatural. A mi juicio el pensamiento religioso es más limitado en su campo y bastante más ambicioso en una sola de sus pretensiones".

Por último, a finales de 1969, Lévi-Strauss le dijo a un reportero del New York Times, que había estudiado las culturas primitivas porque no le gustaba el siglo en que había nacido, que la gente no era más que el resultado de "secreciones psicológicas y toxinas morales" por las que otros morían. Esta premisa fundamental y su brillante capacidad de observar las conexiones, constituye la base de su trabajo, original, penetrante y perdurable, según refieren Bohannan y Glazer (1993).

\section{A manera de epílogo}

El estructuralismo fundamentó una nueva concepción metodológica de carácter interdisciplinario, orientado a superar los límites del empirismo y el historicismo dominantes hasta entonces en las diversas escuelas del pensamiento antropológico. Sus postulados influyen tanto en el campo de la Antropología como en el de la Psicología, 
promoviendo cambios en las Ciencias Sociales. En este punto, el aporte fundamental de Lévi-Strauss es haber demostrado la relevancia de la Etnografía para el entendimiento de los procesos culturales y psicológicos. Lévi-Strauss produjo una profunda innovación al haber tomado el dilema vigente en la Antropología acerca de la incompatibilidad entre "naturaleza humana y variabilidad cultural" y presentado a ambas como una estructura unificada, abstracta, que gobierna las variaciones concretas.

Podríamos afirmar que la mayor originalidad del pensamiento levistraussiano radica esencialmente en su afirmación acerca de una "estructura" universal, común a todas las sociedades humanas y subyacentes a la diversidad de manifestaciones concretas. Esta afirmación adquiere mayor importancia si consideramos que antes se pensaba que las "poblaciones exóticas" eran psicológicamente diferentes a nosotros, de modo que estudiarlos tenía relevancia, tanto desde un punto de vista evolutivo como comparativo, o aquella afirmación predominante de la época que identificaba la 'mentalidad primitiva' con la de los niños, como pensaba Levy Bruhl. Lévi-Strauss considera que no es que los miembros de esas sociedades ágrafas estén más cercanos a la naturaleza, todos lo estamos en la medida de nuestras posibilidades. Para este eminente pensador la diferencia radica en la "domesticación" de un pensamiento frente a lo "agreste" del otro, que es el modo de pensar compartido por todos los seres humanos, independiente del tiempo y del espacio.

\section{Obras básicas de Lévi-Strauss traducidas al español}

\section{LÉVI-STRAUSS, Claude}

1968 Las estructuras elementales del parentesco. Buenos Aires: Paidós.

1964 El pensamiento salvaje. México: Fondo de Cultura Económica.

1968 Antropología estructural. Buenos Aires: EUDEBA.

1968 Mitológicas I. Lo crudo y lo cocido. México: Fondo de Cultura Económica.

Elogio de la Antropología. México: Cuadernos del Pasado y del Presente 2.

El mismo texto fue publicado en 1976, bajo el título Crítica de la antropología, Antigua Casa Editora Cuervo, Buenos Aires.

1970 Tristes trópicos. Buenos Aires: EUDEBA.

El oso y el barbero. Barcelona: Cuadernos Anagrama 2.

1971 El totemismo en la actualidad. México: Fondo de Cultura Económica.

1971 Mitológicas II: De la miel a las cenizas. México: Fondo de Cultura Económica.

1974 Estructuralismo y ecología. Barcelona: Cuadernos Anagrama 9.

1976 Mitológicas III: El origen de las maneras de mesa. 2. ${ }^{a}$ ed. México: Siglo XXI Editores.

1981 La vía de las máscaras. México: Siglo XXI Editores.

1981 La identidad. Barcelona: Edit. Pretil. Antropología estructural II. México: Siglo XXI Editores.

1983 Mitológicas IV: El hombre desnudo. 3. ${ }^{a}$ ed. México: Siglo XXI Editores.

1985 La palabra dada. Madrid: Espasa Calpe.

1985 La mirada alejada. Madrid: Edit. Argos Vergara, El mismo texto ha sido publicado con el título Mirando a lo lejos. Buenos Aires: Emecé Editores, 1986.

1990 Mito y significado. 2. ${ }^{\mathrm{a}}$ ed. Alianza Editorial, Libro de Bolsillo. 